\title{
Editorial The methodology of contemporary macroeconomics
}

The Editorial Board of Economics and Business Review intended to devote this special issue to the emerging field of the philosophy of economics. This subdiscipline of our profession is rather in its youth, however, showing the signs of maturity. Philosophy or methodology of economics has several international organizations, leading journals and even book series - all of which serve only one purpose: to interlink those researchers who make considerable efforts to approach our traditional problems from a different point of view. As Polish researchers are particularly active in this field, the pleasure was mine when the EBR asked me to join this interesting project as a guest editor. I am really indebted to the Editorial Board for initiating me in the tough process of setting up this issue from the first occurrence of the idea. Thanks to our joint efforts, we could team up prominent and illustrious authors to share their thoughts regarding the sophisticated question of the methodology of contemporary macroeconomics. It is an additional source of pleasure for me that we really have an international cooperation of authors from the United Kingdom through the Netherlands and Poland to Hungary, where even the ages of our contributors show a great variety. It was an explicit editorial policy of ours to encourage the dialogue between researchers of different ages and countries. By having rejoinders ${ }^{1}$ to all our papers, we have both interesting pairs of senior and early-stage researchers and the hope of creating the possibility of new and burgeoning research links.

Why macro, you may ask. We are living in an age where the former myth of stable macroeconomies is dead once and for all. After severe world economic turbulences, macroeconomics faced serious challenges. Even though it is exactly such recurrent episodes of falls and rises in general macroeconomic performance that gave birth macroeconomics some decades ago, since 2008 there have been several voices claiming that modern macroeconomics, be it business-cycle theory or growth theory, has lost its relevance as to practical economic policy. Understanding business cycles has been a central topic in modern macroeconomics for decades. Business cycles are complex phenomena, so the underlying causal structure is difficult to disentangle. Different

\footnotetext{
${ }^{1}$ Rejoinders published are not peer-reviewed and do not necessarily reflect the views and opinions of the Editorial Board.
} 
schools of the economic thought have attributed different causes to the same event. Neoclassical orthodoxy tries to address the problem in a choice-theoretic framework, while heterodox currents challenge this approach by emphasizing a multitude of possible social, institutional or even political causes. Due to these efforts, by now we not only have known a great deal about the nature of business cycles but also about the possible ways of treatment. The high importance of these theories is indicated by the number of Nobel prizes awarded for the related achievements.

However, it is easy to realise that the difference between the approaches stems from the difference between the methodologies along which the traditions try to address their chosen problems. Locking away in their own methodologies has triggered a demarcation between the different schools. This process of sharpening demarcation has led to an unfavourable situation in which different schools cannot even communicate with one another, despite all of them contribute to the highly complex endeavour of understanding capitalist economies. This is the reason why I think that the understanding of methodologies must be the first step to the understanding and the reconciliation of the different thoughts in economics. By this special issue we tried to create a new platform for sharing ideas in order that at least our contributors could start new dialogues.

As guest editor I have the privilege of giving a short introduction of the six papers and rejoinders included in this special issue. There occurred some topics around which the contributions of our authors can be easily grouped. Such themes were growth, János Kornai’s oeuvre and Michal Kalecki's contributions to macroeconomics.

Jerzy Osiatyński, a former student of legendary Polish economist Michał Kalecki, outlines ways as to how Kalecki contributed to the evolution of Keynesianism in the decades after the publication of Keynes' General theory. As Keynesianism, especially the Keynesian approach to large-scale macroeconomic fluctuations, has become an idea different from the mainstream business-cycle approach, these insights invite the reader to consider theoretical economics as a complex discipline. One could hardly find a better account of how different approaches complement each other in economics.

Janos Kornai is still the most influential economist in Central Europe who devoted several magnum opuses to the understanding of the command economy. Thanks to him, we know a great deal about this episode of economic history today. However, his works are not only memories of the past. It is sad but true that Central European economies inherited several problems of the preceding socialist era. Our current macro-social problems can easily be traced back to the crisis phenomena of socialism. Corruption, the over-emphasized role of the state, poverty, wage tensions or inadequate education: all these challenges are rooted in the past and for the ultimate sources of our present-day problems stem from the past, we also need to look back on the past when it comes to for- 
mulizing our solutions. But for Kornai's intellectual efforts, I am sure we would be hopeless at even realizing the problems, let alone seeking the answers. As Janos Kornai was awarded a Doctor Honoris Causa from Poznań University of Economics already in 1978, it was an explicit editorial policy to place emphasis on the assessment of his intellectual heritage and to render a tribute on occasion of his $90^{\text {th }}$ birthday. Accordingly, László Csaba reviewed Kornai's oeuvre from a unique point of view. For Kornai's critique of the neoclassical orthodoxy is still relevant, László Csaba gave a detailed analysis of the relationship between formalized mainstream economics and Kornai's comparative economics. This is the line along which Kornai's lifework unfolds.

Michael Joffe turned his attention to a micro-founded theory of economic growth. As is well-known, the microfoundations make up one of the most problematic areas of modern macroeconomics. Not even the mathematical tractability of the project is often-questioned, but also the very idea of placing macroeconomics on a microeconomic footing is widely debated. Michael Joffe takes a sceptical attitude towards mainstream growth theories for these models in his view fail to give account of even the main features of economic growth. His answer is to suggest a more comprehensive approach to include more factors than the commonly known growth theories. Michael Joffe's paper proved to be a thought-provoking initiation in addressing a well-known problem from an ignored point of view.

It is time to say something positive about neoclassical orthodoxy and modern macroeconomics as such. It is Pawel Kawalec who undertakes this task which seems considerably difficult to complete in a day and age when countermainstream currents are growing in both strength and intensity. Very recently Paul Romer made an effective attack against DSGE-models on methodological grounds. Pawel Kawalec made efforts to dig deep in order to take up the quarrel of DSGE-models at the root of the problem. By so doing Kawalec turns to the history of economics, so his paper is part of a growing number of treatises that take the history of economics and economic methodology as two interconnected and closely related subdisciplines. Judged by scientific representation standards DSGE-models seem to meet the common epistemic standards of scientific research.

Peter Mihályi focused on one item of Kornai's lifework. In 1972 Kornai published his most debated book under the title Anti-equilibrium which was supposed to be a grandiose mainstream-critique. Even though as a critique this work of Kornai could only moderately succeed overseas, in Europe and especially in Central Europe Anti-equilibrium triggered a completely new line of thinking. As a result a new standard emerged to address the relationship of macro-models to reality. A more direct relationship has become established recently which has led to the need of a dedicated European Economics. However, oftentimes Anti-equilibrium is still regarded as Kornai's most influential book, having opened the avenue for new research initiatives. In this vein 
Peter Mihályi devoted his paper to a simple micro-level observation provoked by the Anti-equilibrium according to which there are some common symptoms both in command and competitive economies. Peter Mihályi's paper proved to be a genuine example as to how to interconnect micro- and macro-levels outside the mainstream camp.

The closing paper by Peter Galbács discusses some general methodological problems of modern macro. The paper aims at clarifying why and how methodology could contribute to both the correct interpretation and the improvement of theoretical considerations. On methodological grounds the author places emphasis on the relationship between the different theoretical and practical approaches to the same social reality.

At the end of this editorial note, it is time for me to call upon our contributors to speak for themselves. I hope, this special issue will turn out to be a trigger for new lines of discussion and for a partnership of our authors.

Peter Galbács

Guest editor 